\title{
Influence of tumor location on short- and long-term outcomes after laparoscopic surgery for rectal cancer: a propensity score matched cohort study
}

Hong Yang ${ }^{\dagger}$, Zhendan Yao ${ }^{\dagger}$, Ming Cui, Jiadi Xing, Chenghai Zhang, Nan Zhang, Maoxing Liu, Kai Xu, Fei Tan and Xiangqian Su ${ }^{*}$ (D)

\begin{abstract}
Background: This study aimed to evaluate the short- and long-term outcomes after laparoscopic resection for low rectal cancer (LRC) compared with mid/high rectal cancer (M/HRC).

Methods: Patients with rectal cancer undergoing laparoscopic resection with curative intent were retrospectively reviewed between 2009 and 2015. After matched 1:1 by using propensity score analysis, perioperative and oncological outcomes were compared between LRC and M/HRC groups. Multivariate analysis was performed to identify independent factors of overall survival (OS) and disease-free survival (DFS).

Results: Of 373 patients who met the criteria for inclusion, 198 patients were matched for the analysis. Laparoscopic surgery for $L R C$ required longer operative time $(P<0.001)$ and more blood loss volume $(P=0.015)$ compared with M/HRC, and the LRC group tended to have a higher incidence of postoperative complications $(16.2 \%$ vs. $8.1 \%, P=0.082)$. There was no significant difference in local recurrence between the two groups $(9.1 \%$ vs. $4.0 \%, P=0.251$ ), whereas distant metastasis was inclined to be more frequent in LRC patients compared with $\mathrm{M}$ / HRC (21.2\% vs. $12.1 \%, P=0.086)$. The LRC group showed significantly inferior 5 -year OS $(77.0 \%$ vs. $86.4 \%, P=0.033)$ and DFS $(71.2 \%$ vs. $86.2 \%, P=0.017)$ compared with the M/HRC group. Multivariate analysis indicated that tumor location was an independent predictor of DFS ( $H R=2.305,95 \% \mathrm{Cl} 1.203-4.417, P=0.012)$.
\end{abstract}

Conclusion: Tumor location of the rectal cancer significantly affected the clinical and oncological outcomes after laparoscopic surgery, and it was an independent predictor of DFS.

Keywords: Low rectal cancer, Mid/high rectal cancer, Laparoscopic surgery, Oncological outcomes, Propensity score matching

\footnotetext{
* Correspondence: suxiangqian@bjmu.edu.cn

${ }^{\dagger}$ Hong Yang and Zhendan Yao contributed equally to this work. Key laboratory of Carcinogenesis and Translational Research (Ministry of Education), Department of Gastrointestinal Surgery IV, Peking University Cancer Hospital \& Institute, 52 Fucheng Road, Haidian District, Beijing 100142, PR China
}

C C The Author(s). 2020 Open Access This article is licensed under a Creative Commons Attribution 4.0 International License, which permits use, sharing, adaptation, distribution and reproduction in any medium or format, as long as you give appropriate credit to the original author(s) and the source, provide a link to the Creative Commons licence, and indicate if changes were made. The images or other third party material in this article are included in the article's Creative Commons licence, unless indicated otherwise in a credit line to the material. If material is not included in the article's Creative Commons licence and your intended use is not permitted by statutory regulation or exceeds the permitted use, you will need to obtain permission directly from the copyright holder. To view a copy of this licence, visit http://creativecommons.org/licenses/by/4.0/ The Creative Commons Public Domain Dedication waiver (http://creativecommons.org/publicdomain/zero/1.0/) applies to the data made available in this article, unless otherwise stated in a credit line to the data. 


\section{Background}

Rectal cancer is one of the most common malignant diseases worldwide. Nowadays, surgery remains the cornerstone for the treatment of rectal cancer. However, the treatment strategy for rectal cancer has changed dramatically in the past decades, for instance, the introduction of total mesorectal excision (TME), neoadjuvant chemoradiotherapy and minimally invasive surgery. Laparoscopic surgery for rectal cancer is widely performed all over the world in recent years. A number of clinical studies including some randomized clinical trials have confirmed that laparoscopic surgery was feasible and safe for rectal cancer, with favorable short-term benefits and similar oncological outcomes compared with open surgery [1-7]. Laparoscopic surgery for rectal cancer is considered to be a technically demanding procedure, especially for low rectal cancer. Some studies have already revealed that the tumor distance from the anal verge was related to the difficulty of laparoscopic surgery [8, 9]. Although several studies have explored the impact of rectal cancer height on clinical management and outcomes in patients undergoing curative resection, few studies have particularly compared the clinical and oncological outcomes of laparoscopic surgery at different heights of rectal cancer [10-13].

Therefore, the aim of the present study was to evaluate the influence of tumor location on short- and long-term outcomes of rectal cancer after laparoscopic resection with curative intent by propensity score analysis.

\section{Methods}

\section{Patients}

We retrospectively reviewed the records of all patients with histologically proven rectal adenocarcinoma who underwent laparoscopic resection with curative intent at the Department of Gastrointestinal Surgery IV, Peking University Cancer Hospital between 2009 and 2015. All the operations were performed laparoscopically by a same surgical team with rich experience in laparoscopic surgery. Patients with distant metastases, emergent surgery, palliative resection, combined evisceration, concurrent malignancies or a history of other malignancies within 5 years were excluded. This study was approved by the Research Ethics Committee of Peking University Cancer Hospital \& Institute.

\section{Interventions}

The treatment decision was based on the location and stage of the disease. All patients were evaluated by means of digital rectal examination, tumor marker levels (CEA, CA19-9 and CA72.4), chest radiography or computed tomography (CT), abdominal and pelvic CT, pelvic magnetic resonance imaging, and colonoscopy biopsy. In addition, endorectal ultrasonography was used in patients with low rectal cancer (LRC). LRC was defined as the lower edge of the tumor located less than 5 $\mathrm{cm}$ from the anal verge, while mid/high rectal cancer (M/HRC) as being above this level, which was assessed by preoperative colonoscopy.

Patients with locally advanced mid-low rectal cancer (defined as tumor located within $10 \mathrm{~cm}$ from the anal verge, with clinical stage $\geq \mathrm{T} 3$ or $\mathrm{N}+$ ) were recommended to receive neoadjuvant therapy (NAT) in the form of long-course chemoradiotherapy (50.6 Gy in 22 fractions, 5 times per week over a month). Capecitabine $(825 \mathrm{mg} /$ $\mathrm{m}^{2}$ orally twice per day) was administered synchronously with radiotherapy. Surgery based on the principle of TME was performed within 6 to 10 weeks after the completion of radiotherapy, whereas patients without NAT underwent curative resection immediately.

The laparoscopic surgery was performed using five ports, same standardized principle and procedure were applied in most cases. The type of surgery either restorative or non-restorative was primarily depended on the distance of rectal cancer from the anal verge and the surgeon's judgment during the operation. Restorative surgery was defined as low anterior resection (LAR). Non-restorative surgery included abdominoperineal resection (APR), extralevator abdominoperineal excision (ELAPE), and Hartmann's procedure. Inferior mesenteric artery was divided proximal or distal to the left colic artery bifurcation, which was decided by the operating surgeon. Lymph node dissection was started near the origin of the inferior mesenteric artery. Mobilization of the sigmoid colon and rectum was required to comply with the principles of TME or partial mesorectal excision if the tumor was in the upper part of the rectum. Endoscopic linear staplers were used to divide the rectum to achieve a safe distal resection margin. The specimen was removed through a small incision using the port in the lower left quadrant or the anus. Transection of the bowel was performed extracorporeally. End-to-end anastomosis was then performed intracorporeally using the double stapling technique. Protective stoma was selectively performed according to tumor location and intraoperative conditions. APR or ELAPE was recommended when the levator muscle was invaded or preservation of the anus was impracticable. The perineal surgery and terminal colostomy were performed as described in the literature [14].

Pathologic evaluation was performed according to the American Joint Committee on Cancer TNM staging system (the seventh edition) [15]. Histopathologic results were independently reviewed by 2 pathologists. Positive circumferential resection margin (CRM) was defined as the distance from the specimen surface to the primary tumor or any tumor deposit $\leq 1 \mathrm{~mm}$. About 4 weeks after surgery, patients with stage III or stage II disease with 
risk factors (poorly differentiated, peritoneal and serosal involvement, lymphovascular or perineural invasion, harvested lymph nodes less than 12 or positive CRM) were recommended to receive adjuvant chemotherapy (using mFOLFOX6, CapeOX or capecitabine alone) for 6 months. Adjuvant chemotherapy was also recommended for patients who received NAT.

\section{Follow-up}

Patients were scheduled for follow-up every 3 months for the first 2 years after surgery, every 6 months for the next 3 years, and yearly thereafter. Follow-up examinations included a physical examination, complete blood cell count, blood biochemistry and serum CEA, CA19-9 and CA72.4 levels. Chest radiography or CT, abdominal and pelvic CT were performed every 6 months, and a colonoscopy was performed annually after the surgery. Local recurrence was defined as clinical, radiological, or pathologic evidence of malignancy near the site of surgical excision or draining lymph nodes. Distant metastasis was defined as recurrent disease in other organs. Overall survival (OS) was defined as the time from the day of surgery to that of death. Disease-free survival (DFS) was calculated from the day of surgery to that of any recurrence.

\section{Statistical analysis}

Propensity score analysis was performed with SPSS (version 22.0, IBM Corporation, Chicago) including REssentials for SPSS and R version 2.15.3 software. Based on tumor location (LRC and M/HRC), patients were matched 1:1 by propensity score (nearest neighbor matching with logistic regression, caliper 0.2 without replacement) using the covariates age, sex, American Society of Anesthesiologists (ASA) score, body mass index (BMI), NAT, tumor differentiation, pathological $\mathrm{T}$ and $\mathrm{N}$ stage, TNM stage, lymphovascular invasion, perineural invasion, preoperative CEA, CA19-9 and CA72.4 levels.

Categorical variables were described as numbers with percentages and compared with either a chi-square or Fisher's exact test. Continuous variables were expressed by median and range and analyzed using Mann-Whitney $\mathrm{U}$ test. OS and DFS were estimated using a KaplanMeier model, and comparisons were analyzed with the log-rank test. Parameters found to be associated with survival by the univariate analysis (based on a $P$-value $<$ 0.05) were entered into a multivariable Cox regression analysis. A $P$-value of $<0.05$ was considered statistically significant.

\section{Results}

According to the inclusion and exclusion criteria, a total of 373 patients were enrolled in our analysis, including
138 patients in the LRC group and 235 patients in the $\mathrm{M} / \mathrm{HRC}$ group. After propensity score matching at a ratio of 1:1 based on the variables mentioned above, 99 LRC patients were matched with $99 \mathrm{M} / \mathrm{HRC}$ patients.

\section{Characteristics and short-term outcome for the total cohort}

The clinicopathologic characteristics of the patients are summarized in Table 1. In the total cohort, there were more elderly patients in the M/HRC group compared with the LRC group $(P=0.027)$. The pathological $\mathrm{T}$ stage and TNM stage of tumors were more advanced in the $\mathrm{M} / \mathrm{HRC}$ group than in the LRC group $(\mathrm{P}<0.001$ and $P=0.002)$. Perineural invasion happened more often in the M/HRC group $(P=0.009)$, while more patients received NAT in the LRC group $(\mathrm{P}<0.001)$. There were no statistical differences in the aspect of other clinicopathologic factors between the two groups.

Operative results of the patients are shown in Table 2. Of all cases, more patients underwent non-restorative surgery in the LRC group $(\mathrm{P}<0.001)$, and in patients receiving restorative surgery, more patients beared protective ostomy in the LRC group compared with the M/ HRC group $(\mathrm{P}<0.001)$. Meanwhile, the LRC group had longer operative time and more blood loss volume than the $\mathrm{M} / \mathrm{HRC}$ group $(\mathrm{P}<0.001)$. There were no significant differences between the two groups in terms of the distal resection margin, CRM status and conversion to open surgery, except for a smaller number of harvested lymph nodes in the LRC group $(\mathrm{P}<0.001)$. The overall morbidity in LRC patients was $17.4 \%$, which was higher than $\mathrm{M} / \mathrm{HRC}$ patients $(10.2 \%, P=0.046)$. However, there were no significant differences in reoperation rate and the length of postoperative hospital stay between the two groups. No mortality occurred in both groups.

\section{Short-term outcome for the matched cohort}

After propensity score matching, there were no longer any significant differences between the LRC group and $\mathrm{M} / \mathrm{HRC}$ group for most of the baseline characteristics, especially for age, pathological TNM stage, perineural invasion and whether receiving NAT (Table 1). Similar to the total cohort, more patients received nonrestorative surgery in the LRC group compared with the $\mathrm{M} / \mathrm{HRC}$ group $(\mathrm{P}<0.001)$. Of the 71 non-restorative procedures, 40 cases of APR, 24 cases of ELAPE and 3 cases of Hartmann's procedure were performed in the LRC group, while 2 cases of APR, 1 case of ELAPE and 1 case of Hartmann's procedure were performed in the M/HRC group. The LRC group demonstrated a statistically significant longer operative time $(\mathrm{P}<0.001)$ and more blood loss volume $(P=0.015)$ when compared with the $\mathrm{M} /$ HRC group. There were no significant differences between the two groups in terms of the distal resection 
Table 1 Demographic and pathological characteristics according to tumor location: overall cohort and matched cohort

\begin{tabular}{|c|c|c|c|c|c|c|}
\hline \multirow[t]{2}{*}{ Variables } & \multicolumn{3}{|c|}{ Overall patients } & \multicolumn{3}{|c|}{ Matched patients } \\
\hline & $\operatorname{LRC}(n=138)$ & $\mathrm{M} / \mathrm{HRC}(n=235)$ & $P$ value & $\operatorname{LRC}(n=99)$ & $\mathrm{M} / \mathrm{HRC}(n=99)$ & $P$ value \\
\hline Sex, n (\%) & & & 0.700 & & & 1.000 \\
\hline Male & $78(56.5)$ & $128(54.5)$ & & $52(52.5)$ & $52(52.5)$ & \\
\hline Female & $60(43.5)$ & $107(45.5)$ & & $47(47.5)$ & $47(47.5)$ & \\
\hline Age (y), n (\%) & & & 0.027 & & & 0.802 \\
\hline$\leq 60$ & $81(58.7)$ & $110(46.8)$ & & $54(54.5)$ & $58(58.6)$ & \\
\hline$>60$ & $57(41.3)$ & $125(53.2)$ & & $45(45.5)$ & $41(41.4)$ & \\
\hline ASA, n (\%) & & & 0.873 & & & 1.000 \\
\hline । & $68(49.3)$ & $112(47.7)$ & & $51(51.5)$ & $51(51.5)$ & \\
\hline$\|$ & $57(41.3)$ & $97(41.3)$ & & $39(39.4)$ & $39(39.4)$ & \\
\hline III & $13(9.4)$ & $26(11.1)$ & & $9(9.1)$ & $9(9.1)$ & \\
\hline BMI $\left(\mathrm{kg} / \mathrm{m}^{2}\right), \mathrm{n}(\%)$ & & & 0.113 & & & 0.669 \\
\hline$<25$ & $73(52.9)$ & $144(61.3)$ & & $52(52.5)$ & $55(55.6)$ & \\
\hline$\geq 25$ & $65(47.1)$ & $91(38.7)$ & & $47(47.5)$ & $44(44.4)$ & \\
\hline Preoperative CEA (ng/ml), n (\%) & & & 0.374 & & & 0.644 \\
\hline$\leq 5$ & $100(72.5)$ & $160(68.1)$ & & $67(67.7)$ & $70(70.7)$ & \\
\hline$>5$ & $38(27.5)$ & $75(31.9)$ & & $32(32.3)$ & $29(29.3)$ & \\
\hline Preoperative CA19-9 (U/ml), n (\%) & & & 0.665 & & & 0.621 \\
\hline$\leq 37$ & $128(92.8)$ & $215(91.5)$ & & $91(91.9)$ & $89(89.9)$ & \\
\hline$>37$ & $10(7.2)$ & $20(8.5)$ & & $8(8.1)$ & $10(10.1)$ & \\
\hline Preoperative CA72.4 (U/ml), n (\%) & & & 0.311 & & & 0.267 \\
\hline$\leq 6.7$ & $121(87.7)$ & $197(83.8)$ & & $85(85.9)$ & $90(90.9)$ & \\
\hline$>6.7$ & $17(12.3)$ & $38(16.2)$ & & $14(14.1)$ & $9(9.1)$ & \\
\hline Tumor differentiation, n (\%) & & & 0.161 & & & 0.592 \\
\hline Well + moderate & $111(80.4)$ & $202(86.0)$ & & $81(81.8)$ & $78(78.8)$ & \\
\hline Poor & 27 (19.6) & $33(14.0)$ & & $18(18.2)$ & $21(21.2)$ & \\
\hline Pathological T stage, n (\%) & & & $<0.001$ & & & 0.461 \\
\hline pT0-2 & $64(46.4)$ & $66(28.1)$ & & $39(39.4)$ & $34(34.3)$ & \\
\hline pT3-4 & $74(53.6)$ & 169 (71.9) & & $60(60.6)$ & $65(65.7)$ & \\
\hline Pathological N stage, n (\%) & & & 0.352 & & & 0.394 \\
\hline pNO & $82(59.4)$ & $128(54.5)$ & & $52(52.5)$ & $46(46.5)$ & \\
\hline $\mathrm{pN} 1-2$ & $56(40.6)$ & $107(45.5)$ & & $47(47.5)$ & $53(53.5)$ & \\
\hline TNM stage, n (\%) & & & 0.002 & & & 0.606 \\
\hline $0-1$ & $52(37.7)$ & $51(21.7)$ & & $31(31.3)$ & $25(25.3)$ & \\
\hline$\|$ & $30(21.7)$ & 77 (32.8) & & $21(21.2)$ & $21(21.2)$ & \\
\hline III & $56(40.6)$ & $107(45.5)$ & & $47(47.5)$ & $53(53.5)$ & \\
\hline Lymphovascular invasion, n (\%) & $13(9.4)$ & $37(15.7)$ & 0.083 & $11(11.1)$ & $13(13.1)$ & 0.663 \\
\hline Perineural invasion, n (\%) & $2(1.4)$ & $18(7.7)$ & 0.009 & $2(2.0)$ & $1(1.0)$ & 1.000 \\
\hline Neoadjuvant therapy, n (\%) & $66(47.8)$ & $27(11.5)$ & $<0.001$ & $30(30.3)$ & $25(25.3)$ & 0.428 \\
\hline Adjuvant chemotherapy, n (\%) & $80(58.0)$ & $117(49.8)$ & 0.126 & 59 (59.6) & 64 (64.6) & 0.464 \\
\hline
\end{tabular}

LRC Low rectal cancer, M/HRC Mid/high rectal cancer, ASA American Society of Anesthesiologists, BMI Body mass index, CEA Carcinoembryonic antigen

margin, CRM status, number of harvested lymph nodes and conversion to open surgery, except for more frequent protective ostomy in the LRC group $(P=0.001)$.
The LRC patients were inclined to have more postoperative morbidity compared with M/HRC patients $(16.2 \%$ vs. $8.1 \%, P=0.082$ ), which may prolong the length of 
Table 2 Perioperative outcomes and recurrence according to tumor location: overall cohort and matched cohort

\begin{tabular}{|c|c|c|c|c|c|c|}
\hline \multirow[t]{2}{*}{ Variables } & \multicolumn{3}{|l|}{ Overall patients } & \multicolumn{3}{|c|}{ Matched patients } \\
\hline & $\operatorname{LRC}(n=138)$ & $\mathrm{M} / \mathrm{HRC}(n=235)$ & $P$ value & LRC $(n=99)$ & $\mathrm{M} / \mathrm{HRC}(n=99)$ & $P$ value \\
\hline Type of operation, n (\%) & & & $<0.001$ & & & $<0.001$ \\
\hline Restorative & $41(29.7)$ & $228(97.0)$ & & $32(32.3)$ & $95(96.0)$ & \\
\hline Non-restorative & $97(70.3)$ & $7(3.0)$ & & $67(67.7)$ & $4(4.0)$ & \\
\hline Operation time (range) (min) & $231(136-468)$ & $182(77-375)$ & $<0.001$ & $231(136-435)$ & $200(77-375)$ & $<0.001$ \\
\hline Blood loss (range) (ml) & $50(10-300)$ & $50(5-2000)$ & $<0.001$ & $50(10-300)$ & $50(5-600)$ & 0.015 \\
\hline Protective ostomy in LAR, $n$ (\%) & $36 / 41(87.8)$ & $106 / 228(46.5)$ & $<0.001$ & 28/32 (87.5) & $52 / 95(54.7)$ & 0.001 \\
\hline Harvested lymph nodes, n (\%) & & & $<0.001$ & & & 0.437 \\
\hline$<12$ & $55(39.9)$ & $49(20.9)$ & & $32(32.3)$ & $27(27.3)$ & \\
\hline$\geq 12$ & $83(60.1)$ & $186(79.1)$ & & $67(67.7)$ & $72(72.7)$ & \\
\hline Distal resection margin $(\mathrm{cm}), \mathrm{n}(\%)$ & & & 0.616 & & & 0.756 \\
\hline$<1$ & $6(4.3)$ & $13(5.5)$ & & $5(5.1)$ & $6(6.1)$ & \\
\hline$\geq 1$ & $132(95.7)$ & $222(94.5)$ & & $94(94.9)$ & $93(93.9)$ & \\
\hline Positive CRM, n (\%) & $4(2.9)$ & $3(1.3)$ & 0.431 & $3(3.0)$ & $3(3.0)$ & 1.000 \\
\hline Conversions, n (\%) & $2(1.4)$ & $8(3.4)$ & 0.334 & $1(1.0)$ & $4(4.0)$ & 0.369 \\
\hline Operative complications, n (\%) & $24(17.4)$ & $24(10.2)$ & 0.046 & $16(16.2)$ & $8(8.1)$ & 0.082 \\
\hline Reoperation, n (\%) & $6(4.3)$ & $3(1.3)$ & 0.082 & $4(4.0)$ & $1(1.0)$ & 0.369 \\
\hline Postoperative LOS (range) (days) & $9(5-26)$ & $9(3-33)$ & 0.172 & $9(5-26)$ & $8(3-33)$ & 0.011 \\
\hline 30-day mortality, n (\%) & $0(0)$ & $0(0)$ & 1.000 & $0(0)$ & $0(0)$ & 1.000 \\
\hline Recurrence, n (\%) & $35(25.4)^{a}$ & $34(14.5)^{b}$ & 0.009 & $28(28.3)^{a}$ & $14(14.1)^{\mathrm{b}}$ & 0.015 \\
\hline Local recurrence & $9(6.5)$ & $4(1.7)$ & 0.019 & $9(9.1)$ & $4(4.0)$ & 0.251 \\
\hline Distant metastasis & $28(20.3)$ & $32(13.6)$ & 0.090 & $21(21.2)$ & $12(12.1)$ & 0.086 \\
\hline Lung & $7(5.1)$ & $10(4.3)$ & 0.715 & $6(6.1)$ & $5(5.1)$ & 0.756 \\
\hline Liver & $1(0.7)$ & $6(2.6)$ & 0.267 & $1(1.0)$ & $2(2.0)$ & 1.000 \\
\hline Other site & $6(4.3)$ & $4(1.7)$ & 0.182 & $3(3.0)$ & $1(1.0)$ & 0.621 \\
\hline Multiple organs & $14(10.1)$ & $12(5.1)$ & 0.065 & $11(11.1)$ & $4(4.0)$ & 0.104 \\
\hline
\end{tabular}

LRC Low rectal cancer, M/HRC Mid/high rectal cancer, LAR Low anterior resection, CRM Circumferential resection margin, LOS Length of stay

a/b Local recurrence and distant metastasis occurred synchronously in 2 cases both in LRC and M/HRC groups

hospital stay for LRC patients to some extent $(P=$ $0.011)$. However, the reoperation rate and 30-day mortality were statistically insignificant between the two groups (Table 2).

\section{Long-term outcome for the matched cohort}

The median follow-up period was 63 months (range, 4124 months) for the matched cohort. Recurrence was observed in 42 patients: 9 had local recurrence, 29 had distant metastasis and 4 developed local and distant recurrence synchronously. As a whole, recurrence was more frequent in the LRC group compared with the M/ HRC group. Separately, the LRC patients tended to have a higher risk of distant metastasis than $\mathrm{M} / \mathrm{HRC}$ patients (21.2\% vs. $12.1 \%, P=0.086)$. However, the incidence of local recurrence was $9.1 \%$ in the LRC group and $4.0 \%$ in the M/HRC group, which was statistically insignificant $(P=0.251)$. The patterns of recurrence are described in detail in Table 2. On Kaplan-Meier analysis, the 5-year
OS was $77.0 \%$ for LRC patients and $86.4 \%$ for M/HRC patients $(P=0.033$, Fig. 1$)$; the 5 -year DFS was 71.2 and $86.2 \%$, respectively $(P=0.017$, Fig. 2$)$.

Based on univariate analysis, age $(p=0.001)$, tumor location $(P=0.033)$, preoperative CEA level $(P=0.043)$, preoperative CA19-9 level $(P=0.006)$, pathological $\mathrm{T}$ stage $(p=0.008), \mathrm{N}$ stage $(\mathrm{P}<0.001)$, lymphovascular invasion $(\mathrm{P}<0.001)$ and postoperative complications $(P=$ $0.003)$ were revealed as significant predictors of OS (Table 3). On multivariate analysis, only age $(\mathrm{HR}=4.236$, 95\% CI 1.915-9.368, $\mathrm{P}<0.001)$, pathological $\mathrm{N}$ stage (HR $=5.006,95 \%$ CI $1.874-13.368, P=0.001)$ and lymphovascular invasion $(\mathrm{HR}=3.086,95 \%$ CI $1.368-6.960$, $P=0.007)$ remained as independent factors of OS (Table 4).

Considering the DFS, univariate analysis revealed age $(P=0.010)$, ASA score $(P=0.036)$, tumor location $(P=$ 0.017), preoperative CA19-9 level $(P=0.019)$, pathological $\mathrm{N}$ stage $(P=0.026)$, number of harvested lymph 


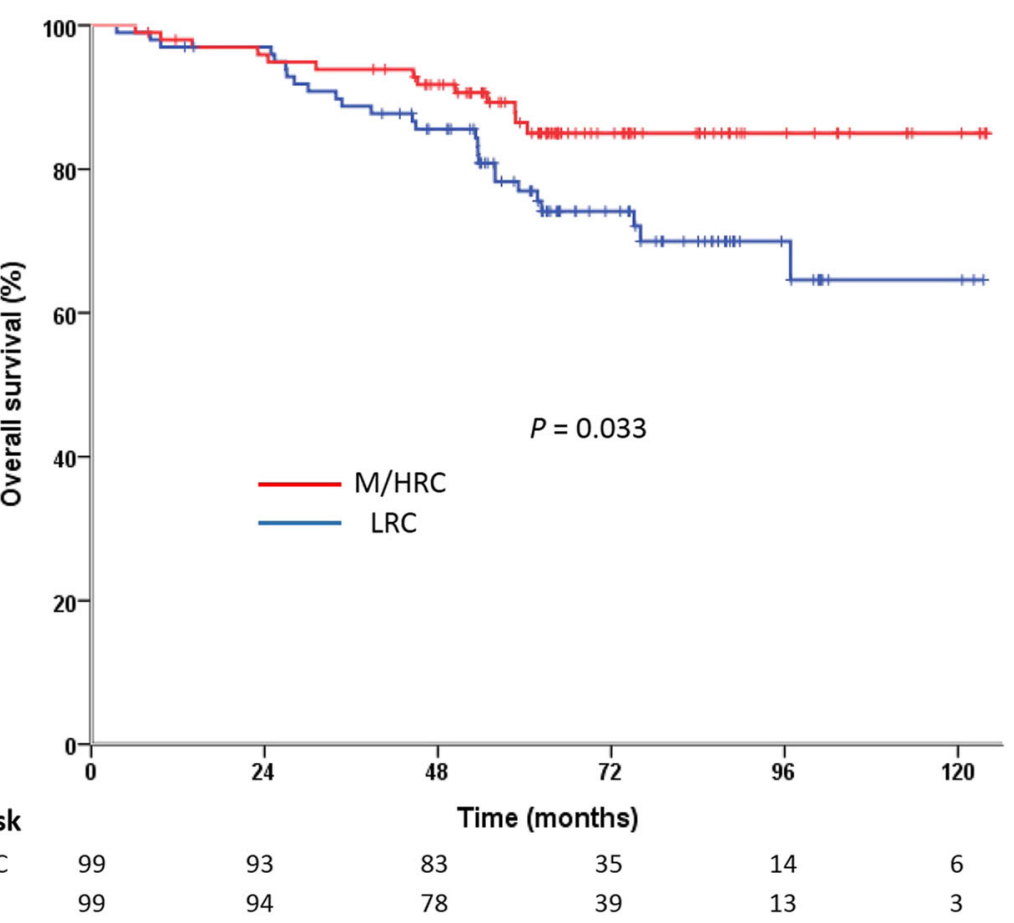

Fig. 1 Kaplan-Meier curves of overall survival for patents of LRC vs. M/HRC

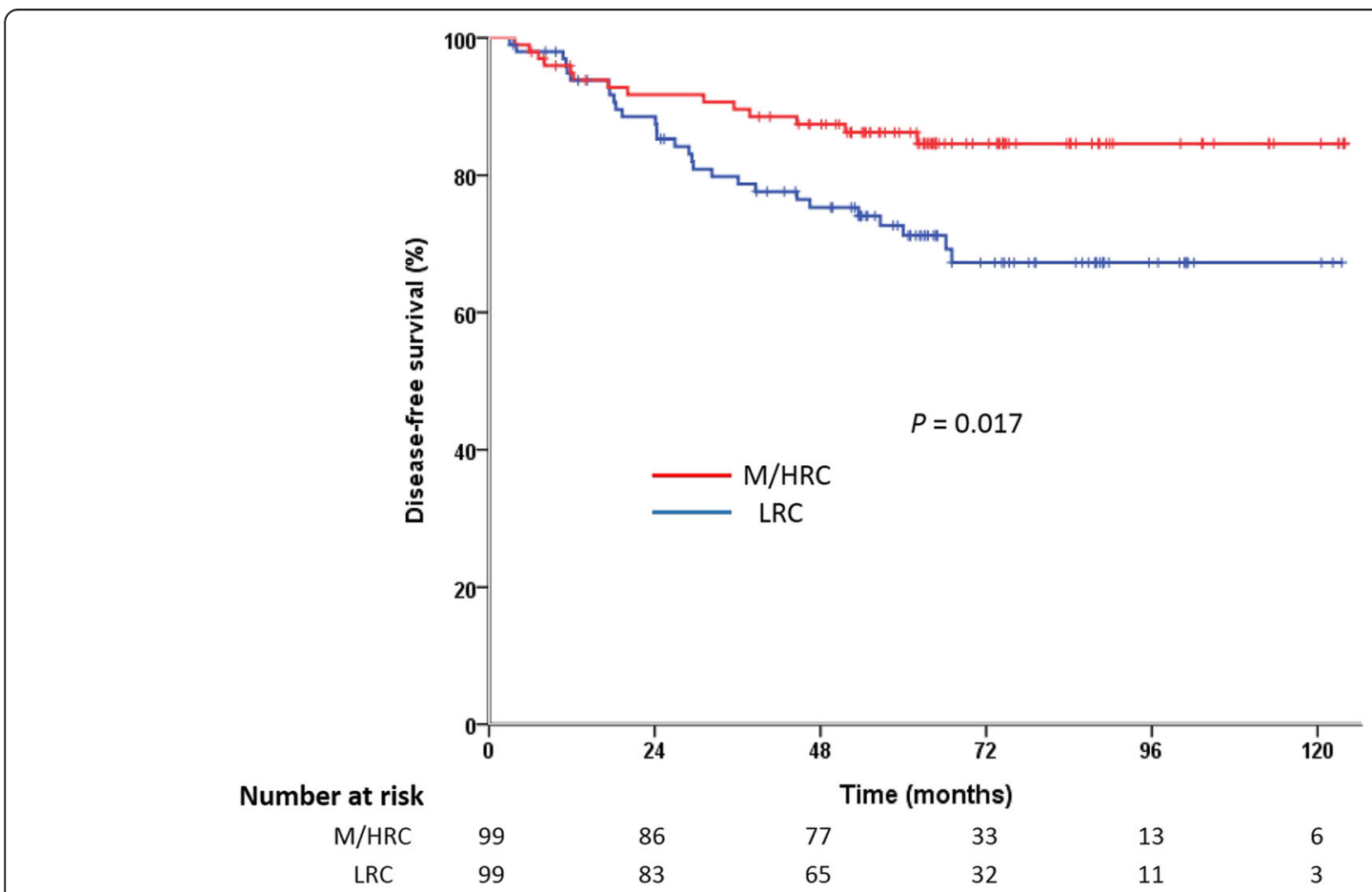

Fig. 2 Kaplan-Meier curves of disease-free survival for patents of LRC vs. M/HRC 
Table 3 Univariate analysis of prognostic factors for overall survival (OS) and disease-free survival (DFS) in matched cohort

\begin{tabular}{|c|c|c|c|c|c|}
\hline Variables & Numbers & 5-year OS (\%) & $P$ value & 5-year DFS (\%) & $P$ value \\
\hline \multicolumn{6}{|l|}{ Sex } \\
\hline Male & 104 & 83.4 & 0.607 & 84.4 & 0.057 \\
\hline Female & 94 & 79.4 & & 72.4 & \\
\hline \multicolumn{6}{|l|}{ Age(y) } \\
\hline$\leq 60$ & 112 & 89.7 & 0.001 & 84.8 & 0.010 \\
\hline$>60$ & 86 & 71.3 & & 70.3 & \\
\hline \multicolumn{6}{|l|}{ ASA } \\
\hline I & 102 & 84.9 & 0.293 & 84.4 & 0.036 \\
\hline$\|-\| \mid$ & 96 & 78.3 & & 72.3 & \\
\hline \multicolumn{6}{|l|}{ BMI $\left(\mathrm{kg} / \mathrm{m}^{2}\right)$} \\
\hline$<25$ & 107 & 77.3 & 0.074 & 79.7 & 0.986 \\
\hline$\geq 25$ & 91 & 86.7 & & 77.7 & \\
\hline \multicolumn{6}{|l|}{ Location } \\
\hline Mid/high & 99 & 86.4 & 0.033 & 86.2 & 0.017 \\
\hline Low & 99 & 77.0 & & 71.2 & \\
\hline \multicolumn{6}{|c|}{ Preoperative CEA (ng/ml) } \\
\hline$\leq 5$ & 137 & 82.6 & 0.043 & 82.2 & 0.141 \\
\hline$>5$ & 61 & 79.1 & & 71.4 & \\
\hline \multicolumn{6}{|c|}{ Preoperative CA19-9 (U/ml) } \\
\hline$\leq 37$ & 180 & 84.0 & 0.006 & 80.6 & 0.019 \\
\hline$>37$ & 18 & 58.8 & & 60.2 & \\
\hline \multicolumn{6}{|c|}{ Preoperative CA72.4 (U/ml) } \\
\hline$\leq 6.7$ & 175 & 82.2 & 0.543 & 79.1 & 0.436 \\
\hline$>6.7$ & 23 & 78.0 & & 75.6 & \\
\hline \multicolumn{6}{|c|}{ Tumor differentiation } \\
\hline Well/moderate & 159 & 84.3 & 0.079 & 79.1 & 0.915 \\
\hline Poor & 39 & 71.0 & & 76.9 & \\
\hline \multicolumn{6}{|l|}{ Pathological T stage } \\
\hline pT0-2 & 73 & 92.0 & 0.008 & 85.2 & 0.288 \\
\hline pT3-4 & 125 & 75.6 & & 74.7 & \\
\hline \multicolumn{6}{|c|}{ Pathological N stage } \\
\hline pNO & 98 & 94.2 & $<0.001$ & 86.0 & 0.026 \\
\hline $\mathrm{pN} 1-2$ & 100 & 68.9 & & 71.2 & \\
\hline \multicolumn{6}{|c|}{ Lymphovascular invasion } \\
\hline Negative & 174 & 86.7 & $<0.001$ & 80.3 & 0.118 \\
\hline Positive & 24 & 46.7 & & 65.5 & \\
\hline \multicolumn{6}{|l|}{ Perineural invasion } \\
\hline Negative & 195 & 82.0 & 0.192 & 79.0 & 0.200 \\
\hline Positive & 3 & 50.0 & & 50.0 & \\
\hline \multicolumn{6}{|l|}{ Type of operation } \\
\hline Restorative & 127 & 86.2 & 0.225 & 81.3 & 0.235 \\
\hline Non-restorative & 71 & 73.5 & & 73.8 & \\
\hline \multicolumn{6}{|c|}{ Harvested lymph nodes } \\
\hline$\geq 12$ & 139 & 82.4 & 0.632 & 82.6 & 0.018 \\
\hline
\end{tabular}


Table 3 Univariate analysis of prognostic factors for overall survival (OS) and disease-free survival (DFS) in matched cohort (Continued)

\begin{tabular}{|c|c|c|c|c|c|}
\hline Variables & Numbers & 5-year OS (\%) & $P$ value & 5-year DFS (\%) & $P$ value \\
\hline$<12$ & 59 & 80.2 & & 69.6 & \\
\hline \multicolumn{6}{|c|}{ Distal resection margin $(\mathrm{cm})$} \\
\hline$\geq 1$ & 187 & 81.7 & 0.871 & 77.5 & 0.096 \\
\hline$<1$ & 11 & 80.8 & & 100.0 & \\
\hline \multicolumn{6}{|c|}{ CRM (mm) } \\
\hline$>1$ & 192 & 81.7 & 0.310 & 80.2 & $<0.001$ \\
\hline$\leq 1$ & 6 & 80.0 & & 33.3 & \\
\hline \multicolumn{6}{|c|}{ Operative complications } \\
\hline No & 174 & 84.8 & 0.003 & 79.7 & 0.569 \\
\hline Yes & 24 & 59.5 & & 71.9 & \\
\hline \multicolumn{6}{|c|}{ Reoperation } \\
\hline No & 193 & 82.3 & 0.121 & 78.1 & 0.263 \\
\hline Yes & 5 & 60.0 & & 100.0 & \\
\hline \multicolumn{6}{|c|}{ Neoadjuvant therapy } \\
\hline No & 143 & 82.4 & 0.519 & 81.9 & 0.035 \\
\hline Yes & 55 & 80.2 & & 70.2 & \\
\hline \multicolumn{6}{|c|}{ Adjuvant chemotherapy } \\
\hline No & 82 & 79.2 & 0.882 & 82.4 & 0.310 \\
\hline Yes & 116 & 83.3 & & 76.2 & \\
\hline
\end{tabular}

ASA American Society of Anesthesiologists, BMI Body mass index, CEA Carcinoembryonic antigen, CRM Circumferential resection margin

nodes $(P=0.018)$, CRM status $(P<0.001)$ and neoadjuvant CRT $(P=0.035)$ as significant predictors of DFS (Table 3). On multivariate analysis, only tumor location (HR $=2.305,95 \%$ CI $1.203-4.417, P=0.012)$, preoperative CA19-9 level $(\mathrm{HR}=2.362,95 \%$ CI $1.014-5.505, P=$ 0.046), pathological N stage ( $\mathrm{HR}=2.438,95 \%$ CI 1.239 4.797, $P=0.010)$ and CRM status $(\mathrm{HR}=8.609,95 \% \mathrm{CI}$ $2.826-26.228, \mathrm{P}<0.001)$ were independent predictors of DFS (Table 4).

\section{Discussion}

Over the past few decades, minimally invasive surgery has been introduced into the treatment of rectal cancer, and more excisions were performed laparoscopically. Our center is one of the earliest medical institutions to carry out laparoscopic resection of rectal cancer in China. In the present study, laparoscopic surgery for LRC required longer operative time and more blood loss volume than M/HRC. The main reason for this was that the difficulty of laparoscopic resection for LRC may be increased due to narrow space and complex anatomy at the bottom of the pelvic, and requiring more nonrestorative surgery or protective ostomy during operation. Though a trend to higher overall morbidity was observed in the LRC group compared with the M/HRC group, which may prolong the duration of postoperative hospital stay, the reoperation rate and 30-day mortality did not increase. Akiyoshi et al. [8] demonstrated that the tumor distance from the anal verge was one of the independent predictors of pelvic operative time and postoperative morbidity. Ogiso et al. [9] also concluded that tumor location was an independent predictor of operative time, which was related to intraoperative blood loss.

In addition, our results showed that 5-year OS and DFS rates were poorer for LRC patients compared with M/HRC patients after laparoscopic surgery, which is consistent with previous literatures [10, 14], although these studies were not focused exclusively on laparoscopic surgery. Chiang et al. [10] noted that the rectal cancer level significantly affected the long-term survival and patterns of distant metastases for patients who underwent surgical resection. Compared with mid-rectal and upper-rectal cancers, LRC had the worst prognosis. Cheng et al. [14] divided T3/T4 rectal cancer patients who underwent surgery into high and mid/low rectal cancer, they found that patients with stage III high rectal cancer demonstrated better prognosis than those with $\mathrm{mid} /$ low rectal cancer, and tumor location was an independent prognostic factor for long-term survival. However, other studies have come to different conclusions, meaning that tumor location has no influence on longterm outcome. Bhangu et al. [11] concluded that low height of rectal cancer after curative surgery did not lead 
Table 4 Multivariate analysis of prognostic factors for overall survival (OS) and disease-free survival (DFS) in matched cohort

\begin{tabular}{|c|c|c|c|c|c|c|}
\hline \multirow[t]{2}{*}{ Variables } & \multicolumn{3}{|l|}{ OS } & \multicolumn{3}{|l|}{ DFS } \\
\hline & $\mathrm{HR}$ & $95 \% \mathrm{Cl}$ & $P$ value & $\mathrm{HR}$ & $95 \% \mathrm{Cl}$ & $P$ value \\
\hline Age(y) & & & $<0.001$ & & & 0.172 \\
\hline$\leq 60$ & 1 & & & 1 & & \\
\hline$>60$ & 4.236 & $1.915-9.368$ & & 1.606 & $0.813-3.170$ & \\
\hline ASA & & & - & & & 0.071 \\
\hline 1 & & & & 1 & & \\
\hline$\|-\| I$ & & & & 1.952 & $0.943-4.040$ & \\
\hline Location & & & 0.099 & & & 0.012 \\
\hline Mid/high & 1 & & & 1 & & \\
\hline Low & 1.801 & $0.894-3.629$ & & 2.305 & $1.203-4.417$ & \\
\hline Preoperative CEA (ng/ml) & & & 0.908 & & & - \\
\hline$\leq 5$ & 1 & & & & & \\
\hline$>5$ & 0.954 & $0.431-2.110$ & & & & \\
\hline Preoperative CA19-9 (U/ml) & & & 0.901 & & & 0.046 \\
\hline$\leq 37$ & 1 & & & 1 & & \\
\hline$>37$ & 1.061 & $0.420-2.680$ & & 2.362 & $1.014-5.505$ & \\
\hline Pathological T stage & & & 0.340 & & & - \\
\hline pT0-2 & 1 & & & & & \\
\hline pT3-4 & 1.579 & $0.618-4.035$ & & & & \\
\hline Pathological N stage & & & 0.001 & & & 0.010 \\
\hline pNO & 1 & & & 1 & & \\
\hline $\mathrm{pN} 1-2$ & 5.006 & $1.874-13.368$ & & 2.438 & $1.239-4.797$ & \\
\hline Lymphovascular invasion & & & 0.007 & & & - \\
\hline Negative & 1 & & & & & \\
\hline Positive & 3.086 & $1.368-6.960$ & & & & \\
\hline Harvested lymph nodes & & & - & & & 0.093 \\
\hline$\geq 12$ & & & & 1 & & \\
\hline$<12$ & & & & 1.955 & $0.895-4.270$ & \\
\hline CRM (mm) & & & - & & & $<0.001$ \\
\hline$>1$ & & & & 1 & & \\
\hline$\leq 1$ & & & & 8.609 & $2.826-26.228$ & \\
\hline Operative complications & & & 0.573 & & & - \\
\hline No & 1 & & & & & \\
\hline Yes & 1.267 & $0.556-2.890$ & & & & \\
\hline Neoadjuvant therapy & & & - & & & 0.476 \\
\hline No & & & & 1 & & \\
\hline Yes & & & & 1.333 & $0.605-2.937$ & \\
\hline
\end{tabular}

- Variable not included in multivariate analysis

ASA American Society of Anesthesiologists, CEA Carcinoembryonic antigen, CRM Circumferential resection margin, HR Hazard ratio, CI Confidence interval

to worse survival, LRC showed equivalent oncological outcome compared with M/HRC. Similarly, Khan et al. [12] also found that although the level of rectal cancer affected the use of NAT and R0 resection rate, it did not affect recurrence rate and long-term survival.
In our matched cohort, the pathological TNM stage of LRC and M/HRC patients was nearly equal, so the longterm survival of the two groups was more comparable. Considering there were more patients of LRC received non-restorative surgery compared with $\mathrm{M} / \mathrm{HRC}$, and this 
may have some impact on long-term survival, multivariate analysis was carried out. On multivariate analysis, we came to the conclusion that tumor location remained as an independent predictor for PFS, but not for OS. When comparing the total recurrence between the two groups, LRC patients had higher risk of tumor relapse. This may explain why LRC patients had worse long-term survival than M/HRC patients. However, when analyzed separately, there was no significant difference in the local recurrence rate between the two groups, though the distant metastasis rate tended to be higher in LRC patients. Considering the small number of patients with recurrence in the series, this finding should be regarded with caution. Cheng et al. [14] found that the location of rectal cancer was a significant risk factor for local recurrence, lung metastasis, bone metastasis and systemic lymph node metastasis, as the tumor distance from the anal verge decreased, the risk for recurrence significantly increased. Frambach et al. [16] retrospectively analyzed 378 patients with locally advanced rectal cancer treated with NAT and curative surgery. They concluded that a distance of the tumor from the anal verge $\leq 5 \mathrm{~cm}$ was the risk factor for recurrence, and it was the only factor associated with increased risk of lung metastasis. Since LRC is more prone to distant metastasis after surgery, its perioperative treatment should be strengthened. At present, preoperative radiotherapy combined with intensive chemotherapy for advanced rectal cancer is one of the research hotspots. In addition, some studies have shown that adjuvant chemotherapy is still necessary for patients with obvious tumor downstaging after NAT, even if complete pathological response has been achieved [17, 18].

The results of this study showed that overall positive CRM rate in the matched cohort was lower $(3.0 \%)$ than most previous studies have reported $[3,19,20]$, and did not differ significantly between LRC and M/HRC patients. The COLOR II study [3, 4] presented that positive CRM rate was $10 \%$ after laparoscopic surgery for rectal cancer, and the rate of local recurrence was $5 \%$ at 3 years. The presence of involved CRM after laparoscopic surgery in the ALaCaRT [19] and the ACOSOG Z6051 [20] randomized clinical trials was 12 and 7\%, respectively. While some other studies have reported relatively low positive CRM rates. The COREAN study [1] noted that CRM positivity was $2.9 \%$ after laparoscopic surgery for mid/low rectal cancer after NAT. Park et al. [21] demonstrated that positive CRM rate was $2.3 \%$ after laparoscopic intersphincteric resection for low rectal cancer, and 3-year local recurrence rate was $2.6 \%$. We speculated the main reason for the low rate of positive CRM in our research was that pathologists may have underestimated the rate of CRM involvement. Besides this, all the operations in this study were performed by a same surgical team and may be related to this result, because in this case surgical standards and procedures were easily unified to ensure high quality of operations. However, considering the postoperative local recurrence rate was 9.1 and $4.0 \%$ for LRC and M/HRC patients, respectively, we deem the actual positive CRM rate would be a little higher than observed in this group.

Compared with M/HRC, LRC was more likely to harvest less than 12 lymph nodes in the total cohort. The proportion of dissected lymph nodes less than 12 in the two groups was 39.9 and $20.9 \%$, respectively. This result can be explained by the fact that more patients in the LRC group had received NAT, which accounted for 47.8 and $11.5 \%$ for LRC and M/HRC patients, respectively. Several studies have shown that NAT was frequently associated with decreased number of harvested lymph nodes, regardless of the application of TME principle and appropriate pathologic evaluation [22-25]. Moreover, some of the findings also noted that retrieval of less than 12 lymph nodes in the proctectomy specimen of rectal cancer treated with NAT had no adverse effect on long-term survival and may be a marker of higher tumor response [26-29]. On the contrary, other studies indicated that lymph node yield was an independent predictor of survival in rectal cancer irrespective of NAT [30, 31]. In our matched cohort, propensity score matching basically eliminated the difference in NAT between LRC and M/HRC patients. The number of harvested lymph nodes were equivalent and the results were comparable between the two groups. The univariate analysis showed that harvested lymph nodes less than 12 was an inferior predictor of PFS, which should be taken seriously.

To our knowledge, this is the only study comparing the short- and long-term outcomes of laparoscopic surgery for LRC and M/HRC by propensity score analysis. However, the present study has a few limitations, such as retrospective design and small samples which introduce inherent selection bias and limit the generalizability of the results. Furthermore, in this study, we divided rectal cancer into LRC and M/HRC, mainly referring to the grouping approach of previous literatures $[11,12]$. From a surgical point of view, laparoscopic surgery for low rectal cancer is considered to be more challenging, with higher rates of positive CRM and permanent stoma, whereas the surgical procedures and difficulties of mid and high rectal cancer are more alike. However, this grouping method has some limitations, especially the perioperative treatment is different depending on tumor location, and NAT is more often recommended for mid/ low rectal cancer but less for high rectal cancer. Finally, due to the limitations of patient compliance and economic condition, the treatment options for the cases included in this study were not always reasonable. For 
example, some patients who required NAT accepted surgery immediately, and other patients who were recommended for adjuvant chemotherapy refused it.

\section{Conclusion}

In conclusion, our study showed that tumor location of the rectal cancer significantly affected the clinical and oncological outcomes after laparoscopic surgery. Lower level of the rectal cancer was related to longer operative time and more blood loss volume, and inclined to have higher postoperative morbidity. Patients of LRC presented significantly inferior OS and DFS, and tended to develop more distant metastasis compared to M/HRC. Besides, tumor location was an independent predictor of DFS for rectal cancer after laparoscopic surgery.

\section{Abbreviations}

LRC: Low rectal cancer; M/HRC: Mid/high rectal cancer; OS: Overall survival;

DFS: Disease-free survival; TME: Total mesorectal excision;

CEA: Carcinoembryonic antigen; CT: Computed tomography;

NAT: Neoadjuvant therapy; LAR: Low anterior resection;

APR: Abdominoperineal resection; ELAPE: Extralevator abdominoperineal excision; CRM: Circumferential resection margin; ASA: American Society of Anesthesiologists; BMI: Body mass index

\section{Acknowledgements}

We would like to thank Ms. Beihai Jiang, Ms. Jiabo Di and Ms. Zaozao Wang for their technical assistance.

\section{Authors' contributions}

Study conception and design: HY and XQS. Acquisition of data: HY, ZDY, NZ, MXL, KX and FT. Analysis and interpretation of data: HY, ZDY, MC, JDX, and $\mathrm{CHZ}$. Writing manuscript: HY, ZDY and XQS. All authors read and approved the final manuscript.

\section{Funding}

This study was supported by the National Natural Science Foundation of China (No.81872022, 81672439), Beijing Natural Science Foundation (No.7162039), Capital's Funds for Health Improvement and Research (CFH 2018-2-2153). The funders had no role in the study design, data collection, analysis and interpretation, publication decision or writing of the article.

\section{Availability of data and materials}

The data that support the findings of this study are available on request from the corresponding author. The data are not publicly available due to privacy or ethical restrictions.

\section{Ethics approval and consent to participate}

This is a retrospective study, and all the patients signed the consent for treating before the treatment. This study was approved by the Research Ethics Committee of Peking University Cancer Hospital \& Institute, Beijing, China.

\section{Consent for publication}

Not applicable.

\section{Competing interests}

The authors declare that they have no competing interests.

Received: 7 April 2020 Accepted: 4 August 2020

Published online: 14 August 2020

\section{References}

1. Kang SB, Park JW, Jeong SY, et al. Open versus laparoscopic surgery for mid or low rectal cancer after neoadjuvant chemoradiotherapy (COREAN trial): short-term outcomes of an open-label randomised controlled trial. Lancet Oncol. 2010;11(7):637-45.
2. Jeong SY, Park JW, Nam BH, et al. Open versus laparoscopic surgery for mid-rectal or low-rectal cancer after neoadjuvant chemoradiotherapy (COREAN trial): survival outcomes of an open-label, non-inferiority, randomised controlled trial. Lancet Oncol. 2014;15(7):767-74.

3. van der Pas $M H$, Haglind $E$, Cuesta MA, et al. Laparoscopic versus open surgery for rectal cancer (COLOR II): short-term outcomes of a randomised, phase 3 trial. Lancet Oncol. 2013;14(3):210-8.

4. Bonjer HJ, Deijen $\mathrm{CL}$, Abis GA, et al. A randomized trial of laparoscopic versus open surgery for rectal cancer. N Engl J Med. 2015;372(14):1324-32.

5. Vennix S, Pelzers L, Bouvy N, et al. Laparoscopic versus open total mesorectal excision for rectal cancer. Cochrane Database Syst Rev. 2014;(4): CD005200. https://doi.org/10.1002/14651858.CD005200.pub3.

6. Hida K, Okamura R, Sakai Y, et al. Open versus laparoscopic surgery for advanced low rectal cancer: a large, multicenter, propensity score matched cohort study in Japan. Ann Surg. 2018;268(2):318-24.

7. Schnitzbauer V, Gerken M, Benz S, et al. Laparoscopic and open surgery in rectal cancer patients in Germany: short and long-term results of a large 10year population-based cohort. Surg Endosc. 2020;34(3):1132-41.

8. Akiyoshi $\mathrm{T}$, Kuroyanagi $\mathrm{H}$, Oya $\mathrm{M}$, et al. Factors affecting the difficulty of laparoscopic total mesorectal excision with double stapling technique anastomosis for low rectal cancer. Surgery. 2009;146(3):483-9.

9. Ogiso S, Yamaguchi T, Hata H, et al. Evaluation of factors affecting the difficulty of laparoscopic anterior resection for rectal cancer: "narrow pelvis" is not a contraindication. Surg Endosc. 2011;25(6):1907-12.

10. Chiang JM, Hsieh PS, Chen JS, et al. Rectal cancer level significantly affects rates and patterns of distant metastases among rectal cancer patients post curative-intent surgery without neoadjuvant therapy. World J Surg Oncol. 2014;12:197.

11. Bhangu A, Rasheed S, Brown G, et al. Does rectal cancer height influence the oncological outcome? Colorectal Dis. 2014;16(10):801-8.

12. Khan MAS, Ang CW, Hakeem AR, et al. The impact of tumour distance from the anal verge on clinical management and outcomes in patients having a curative resection for rectal cancer. J Gastrointest Surg. 2017;21(12):2056-65.

13. Cheng $\amalg$, Chen JH, Chen SY, et al. Distinct prognosis of high versus mid/ low rectal cancer: a propensity score-matched cohort study. J Gastrointest Surg. 2019;23(7):1474-84.

14. Habr-Gama A, São Julião GP, Mattacheo A, et al. Extralevator abdominal perineal excision versus standard abdominal perineal excision: impact on quality of the resected specimen and postoperative morbidity. World J Surg. 2017:41(8):2160-7.

15. Wittekind C, Meyer HJ. TNM classification of malignant tumours. 7th ed. Weinheim: Wiley; 2010.

16. Frambach P, Pucciarelli S, Perin A, et al. Metastatic pattern and new primary tumours after neoadjuvant therapy and surgery in rectal cancer. Color Dis. 2018;20(12):0326-34.

17. Dossa F, Acuna SA, Rickles AS, et al. Association between adjuvant chemotherapy and overall survival in patients with rectal cancer and pathological complete response after neoadjuvant chemotherapy and resection. JAMA Oncol. 2018:4(7):930-7.

18. Polanco PM, Mokdad AA, Zhu H, et al. Association of adjuvant chemotherapy with overall survival in patients with rectal cancer and pathologic complete response following neoadjuvant chemotherapy and resection. JAMA Oncol. 2018;4(7):938-43.

19. Stevenson AR, Solomon MJ, Lumley JW, et al. Effect of laparoscopic-assisted resection vs open resection on pathological outcomes in rectal cancer: the ALaCaRT randomized clinical trial. JAMA. 2015;314(13):1356-63.

20. Fleshman J, Branda M, Sargent DJ, et al. Effect of aparoscopic-assisted resection vs open resection of stage II or III rectal cancer on pathologic outcomes: the ACOSOG Z6051 randomized clinical trial. JAMA. 2015:314(13):1346-55.

21. Park JS, Choi GS, Jun SH, et al. Laparoscopic versus open intersphincteric resection and coloanalanastomosis for low rectal cancer: intermediate-term oncologic outcomes. Ann Surg. 2011;254(6):941-6.

22. Wang H, Safar B, Wexner $\mathrm{S}$, et al. Lymph node harvest after proctectomy for invasive rectal adenocarcinoma following neoadjuvant therapy: does the same standard apply? Dis Colon Rectum. 2009;52(4):549-57.

23. de la Fuente SG, Manson RJ, Ludwig KA, et al. Neoadjuvant chemoradiation for rectal cancer reduces lymph node harvest in proctectomy specimens. J Gastrointest Surg. 2009;13(2):269-74.

24. Marks JH, Valsdottir EB, Rather AA, et al. Fewer than 12 lymph nodes can be expected in a surgical specimen after high-dose chemoradiation therapy for rectal cancer. Dis Colon Rectum. 2010;53(7):1023-9. 
25. Morcos B, Baker B, Al Masri M, et al. Lymph node yield in rectal cancer surgery: effect of preoperative chemoradiotherapy. Eur J Surg Oncol. 2010; 36(4):345-9.

26. Klos CL, Shellito PC, Rattner DW, et al. The effect of neoadjuvant chemoradiation therapy on the prognostic value of lymph nodes after rectal cancer surgery. Am J Surg. 2010;200(4):440-5.

27. Damin DC, Rosito MA, Contu PC, et al. Lymph node retrieval after preoperative chemoradiotherapy for rectal cancer. J Gastrointest Surg. 2012; 16(8):1573-80.

28. de Campos-Lobato LF, Stocchi L, de Sousa JB, et al. Less than 12 nodes in the surgical specimen after total mesorectal excision following neoadjuvant chemoradiation: it means more than you think! Ann Surg Oncol. 2013; 20(11):3398-406.

29. Bustamante-Lopez L, Nahas CS, Nahas SC, et al. Understanding the factors associated with reduction in the number of lymph nodes in rectal cancer patients treated by neoadjuvant treatment. Int J Color Dis. 2017;32(6):925-7.

30. Xu Z, Berho ME, Becerra AZ, et al. Lymph node yield is an independent predictor of survival in rectal cancer regardless of receipt of neoadjuvant therapy. J Clin Pathol. 2017;70(7):584-92.

31. Wang $Y$, Zhou M, Yang J, et al. Increased lymph node yield indicates improved survival in locally advanced rectal cancer treated with neoadjuvant chemoradiotherapy. Cancer Med. 2019;8(10):4615-25.

\section{Publisher's Note}

Springer Nature remains neutral with regard to jurisdictional claims in published maps and institutional affiliations.

Ready to submit your research? Choose BMC and benefit from:

- fast, convenient online submission

- thorough peer review by experienced researchers in your field

- rapid publication on acceptance

- support for research data, including large and complex data types

- gold Open Access which fosters wider collaboration and increased citations

- maximum visibility for your research: over $100 \mathrm{M}$ website views per year

At BMC, research is always in progress.

Learn more biomedcentral.com/submissions 